\title{
Alternatives to a New Library Building
}

By KEYES D. METCALF

\begin{abstract}
' 'HE PRICE TAG for a new library build1 ing in these days of high construction costs often comes to twenty times the library's annual budget, or even more. This being the case, alternatives to new construction ought to be considered. Buildings may become inadequate for a variety of reasons; they do not usually wear out, but fashions, standards, and needs change. Inadequate size, however, is usually the most urgent consideration when replacement of a college or university library building is advocated, and it may be appropriate, therefore, to begin by saying something of growth and space.
\end{abstract}

Library collections grow. New acquisitions for the most part do not replace the books that are already available. There are additions, but normally very few subtractions. The staff of a library also grows as the collection becomes larger and more complex and as use increases. Increased use requires increased space for readers. Changes in teaching methods in many institutions often result in larger demands on the library, and no end to this tendency seems to be in sight.

The factors of growth that have been mentioned must be taken into account, even when the institution maintains a student body and faculty of constant size. Libraries grow, but most American colleges and universities are growing rapidly in nearly every respect and expect still further growth.

In spite of the apparent inevitability of library growth, the librarian will certainly be in a better position to support a request for new construction if he has considered and studied carefully all the possible alternatives. This article will try to deal at least superficially with these alternatives and will start by considering
Mr. Metcalf is Librarian Emeritus, Harvard College Library.

additional space needs for books, for readers, and for staff.

\section{SPACE FOR BOOKs}

Obviously, a library ought not to add books indiscriminately. It is rare indeed for acquisition funds to be so plentiful that large quantities of useless material are purchased, but some libraries have made the mistake of accepting practically everything that has been offered to them by gift or exchange. The need for improved selection policies is generally recognized; but, in a well administered library, more rigorous selection promises to improve the quality of what is added, rather than to reduce the quantity.

Discarding is often a more promising method of reducing growth, because not all books that are added to a collection remain useful indefinitely. The problem is to identify those that are no longer worth the space they occupy. Almost any volume may conceivably be useful to someone's research some day. It is diffcult and expensive to select material for discard; the mistakes that are made in the process are more likely to be discovered and to be criticized than those that are made in choosing books to be added to the collections. It is also expensive to change catalogue records as books are withdrawn.

A librarian is conscious of his responbility to scholarship generally. Even if it seems almost certain that a volume will never be used in his own institution, he feels, quite properly, that he ought to try to find a home for it where it will be 
useful, but intelligent relocation of such material is a difficult task and is also costly.

Problems of this kind are being investigated at Yale, Harvard, Chicago, and other institutions. Adequate treatment of them would require a book, rather than part of a single article. It need only be emphasized here that, before he attempts to obtain more shelf space, a librarian ought to satisfy himself that judicious weeding would not free the shelves that he needs and perhaps even make his collections more readily usable.

\section{SPACE FOR READERS}

Since increasing use is one of the best evidences of a library's good health, it may seem paradoxical to suggest the desirability of considering methods of solving space problems by decreasing use. It will certainly not be suggested that use be discouraged by permitting collections or services to deteriorate. But many college and university libraries-particularly, in the large metropolitan areas-those with strong collections, are heavily used by students and professors from other institutions. This is not the place to advocate that they give such service freely, that they charge for it, or that they refuse to give it at all; but something ought to be said of the building costs that are entailed by that use. In most libraries the readers and reader services occupy far more space than books. A fair generalization, based on formulas that will be described in my book on library building planning, is that twenty-five square feet in a reading room, plus twenty-five square feet else- where in the building, are required for each reader and the services he needs. This total of fifty square feet may well cost something like one thousand, two hundred and fifty dollars in construction at today's prices. When the demands on a library approach the limit of its capacity, the student or professor from another institution who uses it does not simply occupy space that would otherwise go to waste; he hastens the day when a new building will be necessary. This point should not be overemphasized, but in a number of our metropolitan institutions it is pertinent.

SPACE FOR STAFF

In most college and university libraries space for staff becomes inadequate before space for books or readers. Staff needs are often neglected because it may be possible to find a corner for one more desk without realizing the loss in efficiency and in productive labor that results from overcrowding. However, a careful rearrangement of work rooms will often make it possible to provide for additional staff members without decreasing their effectiveness.

\section{More Efficient Use of Space}

If a crowded library has few books that ought to be discarded and is serving only readers whom it ought to serve, there may still remain a possibility that, by making better use of the space it occupies, as has just been indicated in the preceding paragraph dealing with space for staff, it can postpone the date at which additional space will be essential. 
Difficult and complex problems can be expected, and it may turn out that costs of alterations and rehabilitation will be greater than can be justified. It is not easy to assess or describe all the factors that ought to be taken into account. Before a decision is made, possibilities in at least six areas should be considered.

1. Provision of shelving for additional books may be practicable. Compact storage of one kind or another may increase the capacity of a stack by fifty per cent or more, even if the stack is of the selfsupporting, multi-tier variety. This is likely, however, to be an expensive installation. If reading areas are larger than necessary, as they may be in an old building, it may be possible to place additional shelving at one end of a reading room. Extra sections of shelving can usually be inserted in one place or another.

2. Additional seats for readers can often be provided by rearrangement of tables and chairs. This may be neither convenient nor aesthetically desirable; many reading rooms are so crowded that it is almost impossible for readers to get to and from the seats, and in many cases the table space for each reader is inadequate for serious study. There are monumental reading rooms, however, with needlessly wide aisles and spaces between tables. It might be pointed out here that the secret of providing as many seats as possible is to make all aisle space do double duty. Twelve or thirteen square feet will normally suffice for a reader's table space and chair. An additional area of about the same size ought to be enough for aisle space, but it is often increased and even doubled if aisles are used which serve seats or shelving on one side only.

3. As already noted, it is usually possible to squeeze in one more desk for one more staff member; the problem is to determine the point at which this creates overcrowding which in turn reduces efficiency. It may be added that in academic libraries overcrowding usually occurs first in the space assigned for staff use because the librarian at the time of construction was too modest in his request or failed to understand the prospective needs, or at least did not convince the authorities that the staff would grow as time went on.

4. It may be possible to make use of halls, lobbies, and what is sometimes called "architectural space"-that is, space that has not hitherto been assigned for library purposes. An unused basement might be brought into use. One difficulty in making better use of basements is that they are often damp, if not wet, and it is expensive to rehabilitate them. Monumental corridors can also be used for exhibits, which may enable the library to devote its former exhibition room to readers of books, or staff.

5. A mezzanine can sometimes be installed over part of a reading room that is two or more stack stories high. The cost of doing this, particularly if it must include air conditioning, may be too great, but the possibility is worth keeping in mind.

6. Many libraries house non-library facilities such as classrooms or administrative offices. Whether or not this use of space has been desirable, it is obvious that when the library needs more space for books, readers and staff, the librarian ought to be prepared to explain why more of the space within the building should be made available to the library.

The best way to determine probable costs when considering any of these six possibilities is to have the structure carefully examined and to obtain an estimate from a reliable builder, after consultation with an architect.

Let us take a hypothetical example. A library finds that the stack capacity of its building can be increased by 100,000 volumes if compact shelving is installed in an unused basement. This would postpone the need for a new building for an additional ten years, but it would require the installation of a new stairway, the 
discarding of old furniture, and the removal of an unused coal bin. Old heating and water pipes that are no longer useful would have to be torn out; a cement floor would need to be replaced and a new floor covering provided for it, as well as new lighting, the refinishing of the ceiling and repainting. The cost of these alterations, plus the new shelves might, because of the difficult problems involved, amount to $\$ 150,000$, or as much as it would cost to build an addition to the library large enough to house the same number of volumes. This might indicate that an addition would be preferable.

There may, however, be other factors to consider. It may be easier to obtain funds for renovation than for new construction. It may be that only a single addition to the building is practicable and that a larger one will be feasible at some later date but not at present.

On the other hand, providing for 100,000 volumes in the old basement may take care of only a fraction of the total needs for space that can be foreseen in the near future; a new building may be the only real solution, and, if so, renovation of the basement may be an expensive way of providing space that will become nearly if not completely useless as soon as a new building is constructed. Yet, if the new building will cost $\$ 1,500,000$, each year that its construction is postponed it might be regarded as saving the income on that sum. This income, at five percent is $\$ 75,000$, which means that renovation of the basement at the cost of $\$ 150,000$, if it enables the library to postpone construction for more than two years, may be an economical course of action. Prospective increases in building costs and business cycles should not be forgotten. Finally, however, a good new building ought to enable a library to provide better services than are possible in an old one. It is difficult indeed to estimate how much this is worth to the institution.
Many a librarian may be sure, both before and after he reads the above paragraphs that only a new building or an addition can provide space of the kind he needs and in sufficient quantity. But his position will be stronger if, before he asks for new construction, he has carefully investigated the alternatives, instead of waiting for others to do it for him. He ought to be prepared to demonstrate that he has considered them and that they will not be satisfactory. He ought to be able to show that the space now available is not being wasted and the cost of continuing to live in the present building, including the cost of required rehabilitation work and the impaired efficiency in services, is greater than the cost of new construction. In the course of examining all the possibilities, he may discover means of postponing such construction; if not, his examination ought to have provided him with convincing arguments for it.

\section{Storage AND Decentralization}

Even if it is proved to the satisfaction of all that a library needs more space, it does not necessarily follow that it must have a completely new central building. An addition or annex of some kind may be practicable, and problems involved in the construction of this sort will be discussed later. First, however, it is desirable to consider whether or not the useful life of a building can be prolonged without altering it by storing a part of the library's collections or by detaching portions of its services and collections and housing them separately. Expedients of this sort should be regarded as forms of decentralization.

Storage should always be considered when a library has many books that are used infrequently but seem to be worth keeping. Such books can be housed more inexpensively in a structure designed for them than in a central library building that occupies expensive quarters.

Cooperative storage with other librar- 
ies offers further advantages if it promises to develop a common pool of resources and to eliminate needless duplication. Three quite different organizations have been pioneering in this field in the past twenty years; the New England Deposit Library, the Hampshire Inter-Library Center, and the Midwest Inter-Library Center. Other libraries have made arrangements for their own storage buildings. These include the University of Michigan, the New York Public Library, the Iowa State University Library. The Bowdoin College Library has used a chapel basement for local storage, and Iowa State a Nissen hut. By making its own arrangements for storage, a library can avoid the complications of cooperation, though it must also forego the advantages. If a new building for other purposes is to be constructed near a library, it may be possible to plan its basement as a storage area. In this way the Harvard Law School Library acquired space for five hundred thousand books beneath the Harvard Graduate Center at a total additional cost for excavation, construction and equipment of less than twentyfive cents per volume. The large mature library is more likely to find storage advantageous than the rapidly growing young institution that normally has not yet acquired an extensive body of infrequently used materials.

Most university libraries are decentralized to some extent, with libraries for professional schools, such as law and medicine, housed separately from the central collection. Other subjects may also be detached. The sciences may develop their libraries near laboratories and museums. It is preferable in most cases to establish a central science library, rather than one for each subject. The humanities and social sciences are more resistant to separation from the main collection, but music, fine arts, Far Eastern language materials, and Slavic literatures are among the subjects that have been housed in separate libraries in some large universities.
Decentralization of this sort has both advantages and disadvantages. It is clearly undesirable when the units are too small to warrant a staff that can provide service during full library hours. Some of the financial considerations that may need to be weighed can be suggested by the situation at Harvard, where replacement of the central library building, the Widener Library, would require thirty million dollars, if the additional cost of the upkeep of the new building were capitalized and added to the cost of construction. Hence, each year that decentralization enables the University to continue to use Widener might be said to represent a saving of one and one-half millon dollars, which can provide a considerable book fund and useful library service.

As has been noted, subject decentralization is common in university libraries. In addition, Harvard has adopted another form of decentralization, within the central library itself, with infrequently used materials in storage at the New England Deposit Library and in basements throughout the University, and with special provision for rare books and manuscripts in the Houghton Library building and for undergraduates in the Lamont Library building. In this way books have been sorted out and housed appropriately, the infrequently used materials in inexpensive storage; the rare books and manuscripts in nearly ideal atmospheric conditions in a building designed to facilitate careful supervision; the undergraduates with a selected collection to which they have free access. Removal of undergraduate services from the Widener building has made it a better place for research, and its stacks are open to those who need access to them, including many undergraduates.

Decentralization of this kind is by no means confined to Harvard. At Michigan the Clements Library houses many of the rare books, and there is also an undergraduate library, as well as a storage 
building. Yale is about to build a separate rare book library, and is prepared to place large quantities of material in either regional or local storage. Cornell has constructed a new central research library and is rehabilitating its old building for use as an undergraduate library. The University of California at Los Angeles is following a similar procedure, as is the University of Alberta.

\section{Annexes And Additions}

If a library must have more space and if storage or other forms of decentralization will not take care of the situation, an alternative to the construction of a new building may still remain-an addition to the existing structure. This is rarely an easy way out. It is usually more difficult to plan a satisfactory addition to an old library building than to design a completely new one. Since it promises to call for only as much new construction as is required by growth, it often appears to be a much more economical solution than a whole new building, and it deserves to be investigated.

The apparent savings, in particular, call for scrutiny. They may turn out to be much smaller than they seem, or may even prove to be nonexistent. A hypothetical, but by no means impossible, example may illustrate this. Let us say that a library occupies fifty thousand square feet of gross space in an area where new construction, including architects' fees but omitting equipment, can be estimated to cost $\$ 20.00$ per square foot. This would seem to mean that providing the same space in a new building will cost one million dollars, and that this amount might be saved if construction of an addition would enable the library to continue to occupy its present quarters. Further analysis, however, might demonstrate that this estimate is far from sound.

It should be said to start with that an architect, a reliable builder, or an experienced library consultant should be consulted on the problem. The following paragraphs indicate why, in some cases, the addition might not turn out to be a wise investment.

1. The gross square footage in the present building may include an unreasonably low percentage of useful space. Analysis might show, for instance, that 50 per cent of the total square footage consists of what can be called "architectural," "monumental" or "non-assignable" space. These include such things as lobbies, stairways, corridors, and walls, as well as unusable attics and basements. It is impossible to avoid a substantial percentage of such space, but 25 to 35 per cent has proved to be sufficient in many recent library buildings. A new building should always prove to be more efficient and useful. It may, therefore, be possible to demonstrate that 40,000 square feet in a new building could provide as much useful space as the old one does with 50,000 . If so, the $\$ 1,000,000$ shrinks to $\$ 800,000$.

2. It may be necessary to sacrifice space in the present building or in the addition or in both if satisfactory connections are to be provided between the present building and the addition. If this loss amounts to a total of 5,000 feet, it will reduce the value of the new space by $\$ 100,000$ and reduce the $\$ 800,000$ gain to $\$ 700,000$.

3. Because the old building has reading rooms fourteen feet high, it might seem necessary, in order to avoid irregular floor levels, to build higher and therefore more expensive reading rooms in the annex than would otherwise be needed. This may well mean an expenditure of an extra $\$ 100,000$, which must be subtracted, and the $\$ 700,000$ becomes $\$ 600$,000 .

4. It might be impossible to fit new stack heights for full capacity into the old pattern, or if they have to be multitier like the old, desirable flexibility will be sacrificed. This may decrease values by $\$ 75,000$, thus reducing the $\$ 600,000$ to $\$ 525,000$.

5. The cost of breaking through walls 
of the old building to make connections with the annex may be estimated at $\$ 25$,000 , which will bring the net gain down to $\$ 500,000$.

6. It may well be that the old building with an addition would not be as easy to operate as a new one could be, and would require for good service one additional staff member at $\$ 5,000$ a year, or the income on $\$ 100,000$, thus reducing the net advantage of the annex to $\$ 400$,000 .

7. The location of the old building may be such that with an addition a second entrance will be required, which will have to be manned at all times when the building is open. If a completely new building could be so located and planned that two entrances would be unnecessary or that one of them could simply have a crash lock, it would save $\$ 10,000$ per year, or the interest of a capital sum of $\$ 200$,000 , which ought to be deducted from what would be saved by continuing to occupy the old building. This would reduce the $\$ 400,000$ to $\$ 200,000$.

8. There may be serious long-range considerations. The present building, though centrally located in the campus when it was built, may no longer be so due to new construction for classroom buildings, or the addition may fill up all the available space that remains, making any further construction impossible, yet the institution may be growing so rapidly that more space will be needed within a comparatively few years. This means that an addition now will entail a completely new structure in the near future. It is difficult to make any monetary appraisal of these disadvantages, but if the poor location is a $\$ 100,000$ handicap and if the fact that the original building, plus the annex, can be expected to be useful as a library for only ten years is also assessed as a $\$ 100,000$ disadvantage, the saving from using an addition instead of new construction, which started as $\$ 1,000,000$, has changed to no saving at all.
9. Finally, the coup de grace may be provided by consideration of other needs within the institution. The university's fine arts department may badly need a new building that would cost a half a million dollars. It may be ready to accept the old library, which is a handsome and monumental one and could be adapted to serve its purposes. The cost of alterations for this purpose may be little more than would have to be paid for the rehabilitation that would be needed in any case if the building continued to house the library.

This hypothetical illustration has been described as a possible one; this is not to say that it is typical or that there would be many cases in which all the disadvantageous factors that were enumerated would occur. Each situation should be examined to determine which of these factors or others are present. The decision should not be reached without consultation with an architect and perhaps with an experienced builder and possibly with a library consultant. An addition can be an economical solution and can be entirely satisfactory from the library standpoint. This is demonstrated by some of the specific cases that follow.

Wellesley College offers an excellent example of a successful addition to a building, although the original library was nearly fifty years old and was in an architectural style that was impracticable to duplicate. The old building was ideally located, well constructed and attractive. The architects found a reasonably satisfactory solution to the extremely difficult problem of floor levels. Available floor space was more than doubled by the addition which cost considerably less than a completely new building, and it is generally agreed to have been a good solution. The present structure is in most ways more satisfactory functionally than it was in the past.

Smith College successfully added a large new wing to a fifty year old building about a decade ago and is now plan- 
ning two other additions. Both are relatively small and involve few complications. A third and considerably larger addition can be made later if needed. The library is fortunate in its floor levels, and "circulation patterns" throughout the original structure and the additions can be kept simple without undue construction costs or waste of space.

Amherst College, though it has a sturdily constructed building that is as old as Wellesley's or Smith's, is confronted by very difficult problems in attempting to plan an addition because its present multi-tier stack has only $6^{\prime} 9^{\prime \prime}$ in the clear throughout most of its area, and no way has been found to provide direct corridors from the present building to any addition except through the stack.

The University of Connecticut library is only twenty years old, but was expensive to construct and wasteful in the use of space. Satisfactory additions will be difficult because any new reading areas directly connected with the present building will have to have unduly high ceilings. Stack levels are too low to match new ones, and it will be hard indeed to provide a good circulation pattern.

The University of Michigan enlarged its library more than forty years ago by wrapping a new structure around the old one. This proved to be resasonably successful. Thirty years later, however, when plans were considered for wrapping a third building around the second, it was decided that the complications would be too great, and the present undergraduate library was built instead. An addition to the old building may still be worked out later.

The Library of Congress managed to get along in its building for longer than could have been expected in view of its rapid growth from 1900 to 1935 , because it could fill in all or part of three of the four large courts around which it was built.

The University of South Carolina found it unwise a few years ago to add to a twenty year old structure, though adjacent space was available; the existing building was too inflexible and was cut into rooms too small for satisfactory use by internal walls that would have been very difficult and too expensive to remove.

The University of Alberta, finding its library building overcrowded at the early age of nine years, was faced by great difficulties in building an addition. Stack floors were of unequal heights, connecting corridors were lacking, and monumental construction proved to be a very costly handicap.

This list could be enlarged almost indefinitely, and any library contemplating an addition might be well advised if it studied the problems involved at a number of the institutions considered in the preceding paragraphs.

There are relatively few cases in which it is now possible to build a satisfactory and economical large addition to a library that is more than fifty years old. The reasons for this have already been suggested, but it may be desirable to enumerate them here.

1. Modern lighting and ventilation have radically changed requirements for floor heights, and it is generally uneconomical to plan new construction that will match the old.

2. The older architectural styles, Gothic, Renaissance, classical, and to a lesser extent, Georgian (particularly if it has a pitched roof), are often too costly to duplicate; if an addition departs radically from the style of the original building, aesthetic difficulties may be almost insurmountable.

3. The cost of tearing out old walls may be excessive, unless the existing building was planned with a view of facilitating access to new wings.

4. The location of many library buildings has become unsatisfactory for library purposes because of shifts in the position of other activities in the institution.

5. Many a building was planned as a 
complete architectural unit by an architect who did not want to have his "gem" modified or damaged aesthetically by future generations.

This last point calls for further comment. More than one architect has said that he would refuse a commission if his instructions included a requirement that the building be planned in such a way that additions would be readily practicable without impairing it functionally. It would be rash to propose a universal rule that no library building should be planned without a suitable addition in mind, but the presidents and governing boards of colleges and universities ought to realize that most academic and research libraries, unless they are much more mature than 95 per cent of those in this country, still grow at a rate that doubles their space requirements every twenty years or less-every ten years in some cases. Unless the institution is prepared to provide completely new housing for its library every ten or twenty years, it ought to arrange for planned expansion.

The exceptions should not be overlooked. There are mature institutions that have acquired their basic research materials and have library collections growing at the rate of only 2 per cent each year, instead of the prevailing 5 or 10 per cent. If such an institution also has a student body reasonably static in size (an unusual situation at present), it may hope to get along without additions to its central library building for many years, if the building is reasonably adequate now and if the library will make the most of savings in space that are possible by means of microfilming, discarding, storage, and other forms of decentralization. It is recommended that all other institutions deliberate very carefully before they employ an architect who insists that no additions be made to his building.

There are a number of questions that need to be answered before plans are made for an addition.
1. When the present building was planned was an addition contemplated? If so, are there drawings for it that were made then? Are they still suitable? Many architects fortunately have realized that an addition would be needed and have proceeded accordingly. The plan of the main library building of the University of Illinois may be regarded as standard. Repeated additions have been made and still more are practicable. There is room at the rear for almost indefinite expansion of stack and reading areas. The limitations of the Illinois plan are that additional cubicles in the stack are available only in places where there is no outside light, new space for readers and stack may not be in a satisfactory proportion in each addition, and, finally, it is not easy to provide for new staff. It may also be noted that the magnificent monumental reading room over the front entrance does not in 1961 seem as attractive functionally as it did fifty years ago, and this valuable space in the building can not be used to best advantage.

2. Is it possible when adding to a library building to obtain an easy and satisfactory circulation pattern with direct access to the new part of the structure? The University of Florida Library at Gainesville, which was built in 1929 and has already had two additions, is an example of a building that is still in good physical condition but is hard to enlarge because difficult circulation patterns would result and would require the sacrifice of valuable space; moreover sufficient additional space to provide for many years ahead is not available in any direction.

3. Do floor levels in the present building make efficient use difficut? It was not unusual during the past century and, alas, even later to plan a library in which it was impossible on any level, even the main one, to go from one end of the building to the other without ascending or descending a few stairs along the way. American technology has not yet devised 
a satisfactory and inexpensive method of taking a loaded book truck up and down short flights of stairs. Additional elevators may help, but they are expensive, particularly if their mechanism must be capable of making frequent stops a few feet apart. The old Cornell University Library, dating back to the 1890 s, is a good example of what ought not to be done. Shifting of books from one part of the building to another is seriously complicated by the numerous short flights of stairs, many of them without elevator connection. There is also the danger that the users of the building will fall on unexpected stairs. In the Widener building at Harvard, where there were two steps and then a landing just before the main stairway to the reading room began, someone fell every week on the average for thirty years. The two steps were finally replaced by an unattractive ramp which has now saved countless sprains and breaks, to say nothing of bruises. It is recommended that short stairs, primarily for architectural purposes, be avoided wherever possible in library buildings.

4. How large an addition will be required? It is one thing to add a small stack or a small wing for reading areas, increasing the size of an old building by 20 or 25 per cent. It is quite a different matter to build an addition that is larger than the original building, something that is often required in these days of rapid growth. The small addition, if it will provide satisfactory space and will not crowd other buildings or encounter other complications, is likely to be desirable. The large addition is more likely to result in problems because it tends to perpetuate any unfortunate features of the old building, making "the tail wag the dog."

5. How long can the proposed addition, plus the present building, be expected to provide adequate space, and what can be done at the end of this period? Will still another addition then be practicable or is this the last? Are the institution and the space needs of its library growing so rapidly that a much larger building will be needed within twenty years? If so, it may well be uneconomical to enlarge now instead of starting over. In a privately endowed, liberal arts college, such as Smith, an addition may be desirable, even if the existing building is fifty years old. Smith does not expect to increase its student body to any considerable extent. Its library collections are mature enough to be growing only approximaely 2 per cent a year, and the Hampshire Inter-Library Center is available to house and supply infrequently used materials.

But tremendous physical expansion of its library must be expected by a taxsupported state university if it now has 5,000 students but plans to have 15,000 within a generation; if its collections, now no larger than Smith's 400,000 volumes, are growig at the rate of 10 per cent a year; and if it expects to support advanced research in an increasing number of fields. Money may well be saved in this case by replacing a building that is only twenty years old. Each institution has its own problems that must be examined before an intelligent decision can be reached.

6. Are there serious aesthetic obstacles to an addition? Following the style of an older structure is likely to be prohibitively expensive, but building a contemporary flat-top wing on a collegiate Gothic, classical or Georgian building may be very difficult. Even if it is done to the satisfaction of many persons with good taste, it may arouse violent alumni criticism. It has been done successfullythe 1958 addition at Wellesley is an example-but there have been many failures.

7. Are there strategic financial considerations to be weighed? There are cases in which the donor of a building or members of the donor's family will

(Continued on page 362) 
paperback publications. Reviews or book notes published in the college newspaper or lists on various subjects such as "Great Books," "New Paperbacks," "Books Especially Enjoyed by Faculty Members," "Books Especially Enjoyed by Students," may stimulate reading. Prizes may be given to students for the best lists of books suggested for purchase. This device has value as the student becomes acquainted with book selection aids. Book reviews or discussions on radio and television may play an important part in interesting people in reading. Faculty influence on the reading of students is rated very high by all librarians. The most casual mention of a book in class by a well-liked and admired faculty member tends to set wheels in motion. Excerpts read from a book in class may cause a run on a book. Any instructor who teaches so that he arouses intellectual curiosity will stimulate reading on the part of his students. Unplanned, informal meetings between faculty members and students are conducive to read- ing when books enter the conversation. Students may help in stimulating the reading of other students by selecting a week end shelf of books to recommend to their fellow students, by preparing a list of popular reading books in various fields, by getting comments on books students like, by getting students to vote on their favorite books, or by getting students to suggest books for purchase for recreational reading. Informal reading groups may be organized on the campus. A pure reading course may be offered since students sometimes justly complain that they are too busy to read anything except class assignments. An honors reading course based on lists supplied by deans of the various colleges may be established.

Whatever methods used, if you succeed in endowing your students with lifetime reading habits so that reading becomes attractive to them you have done much to aid in the progress of education and in the development of an informed citizenry.

\section{Alternatives to a New Library Building}

(Continued from page 35t)

give funds for an addition but would not contribute to a new structure. The sentimental value of an old building may be so great that it would be unwise to discard it or use it for other purposes. The library of Delaware State College in Dover has occupied the oldest building on the campus for many years-a building that was once the chapel of the slave plantation on which the college developed after the Civil War; students and faculty regard it with great affection as the heart of the institution. The college was fortunate in being able, without materially changing the character of this building, to enlarge it and continue to use it for its library.

Despite all difficulties, the possibilities of an addition ought to be examined before it is decided to give up an old building. It will often be desirable to call in an architect, a builder or a library consultant or all three to make sure that an addition is practicable. The costs ought to be estimated as carefully as possible and the advantages and disadvantages assessed. No simple formula will take the place of thoughtful study in light of the library's future and the institution's educational program.

COLLEGE AND RESEARCH LIBRARIES 